\title{
Адсорбция диметилполисилоксана на графите, антраците, активированном угле из растворов в гексане
}

\author{
(c) 2020 Тихомирова К.В., Лопанов А.Н. \\ Белгородский государственный технологический университет им. В.Г. Шухова, Белгород
}

Поступила в редакцию 5.04.2020 г.

DOI: $10.17308 /$ sorpchrom.2020.20/2954

Выполнен анализ особенностей адсорбции высокомолекулярных веществ на пористых углеродных адсорбентах, заключающихся в низкой скорости диффузии макромолекул, зависимостью величин адсорбции от пористости адсорбента и наличия таких конформаций в адсорбционном слое, которые энергетически не выгодны. Проведена реконструкция конформаций макромолекулы поликарбоксилата по отдельным фрагментам. Получены качественные закономерности распределения макромолекулы поликарбоксилата по поверхности в зависимости от концентрации 1.1-валентного

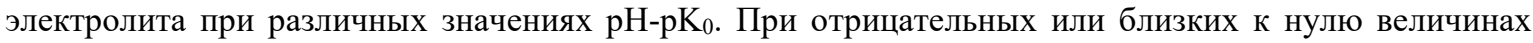
$\mathrm{pH}-\mathrm{pK}_{0}$ степень ионизация слабая и близка к нулю. При достаточно больших значениях $\mathrm{pH}-\mathrm{pK} \mathrm{B}_{0}$ во всех случаях диссоциация возрастает и вследствие сил электростатического отталкивания между отдельными участками макромолекула разворачивается, становится более линейной и в таком виде адсорбируется на поверхности. Величина адсорбции в первую очередь зависит не столько от природы поверхности, сколько от конформации макромолекулы в растворе и среднеквадратичного радиуса степени гидратации. Исследована адсорбция диметилполисилоксана (ПМС-20) из растворов вещества в гексане на графите C-3, активированном угле «Б», ископаемом угле марки «А» Донецкого бассейна (пласт стеклянный). Установлены закономерности адсорбции, заключающиеся в том, что по типу изотермы адсорбции не соответствуют изотермам адсорбции Ленгмюра. Заполнение адсорбционного слоя на графите происходит более медленно, а на антраците и активированном угле боле интенсивно, чем при Ленгмюровской адсорбции. Высказано предположение, что при адсорбции диметилполисилоксана на графите происходит взаимное отталкивание глобул макромолекул, а на антраците и активированном угле высокий адсорбционный потенциал способствует более интенсивному заполнению адсорбционного слоя. Установлена максимальная адсорбционная способность исследованных адсорбентов по отношению к диметилполисилоксану, равная для графита, антрацита, активированного угля соответственно 2; 100, 480 мг/г. Расчетные значения максимальной адсорбционной способности адсорбентов равны соответственно 6; 130; 768 мг/г. Часть пористого пространства антрацита, активированного угля не доступна для адсорбции макромолекул диметилполисилоксана вследствие стерических затруднений.

Ключевые слова: изотермы адсорбции, диметилполисилоксан, графит, антрацит, активированный уголь.

\section{Введение}

Значительное количество современных исследований посвящено адсорбции высокомолекулярных соединений на углеродных адсорбентах, что обусловлено применением углеродных материалов в различных технологических процессах. Так, адсорбция высокомолекулярных соединений (BMC) из растворов является важной стадией в создании углеродных композитов. Адсорбированный слой полимера оказывает большое влияние на способность веществ конденсироваться на межфазной 
поверхности, так как представляет собой оболочку, физико-химические свойства которой определены структурой макромолекул на поверхности вещества - ориентацией, толщиной адсорбционного слоя и энергией взаимодействия с поверхностью. Особенно существенное влияние адсорбция макромолекул влияет на технологические свойства электропроводящих композитов с матрицами силикатов, где в качестве электропроводящей компоненты служат углеродные вещества, такие как графит, антрацит, активированный уголь. Проводя модификацию поверхности путем адсорбции высокомолекулярного вещества из раствора, поверхность углеродных частиц можно сделать гидрофобной или гидрофильной, что важно для технологии карбоновых композитов. Так, гидрофобизацию поверхности и создание условий получения матричного композита при достаточно низком содержании углеродного вещества, порядка 5-10\% масс. можно осуществлять путем нанесения дифильных ВМС на поверхность угольной частицы, например, путем адсорбции диметилполисилоксана на углеродных веществах. Диметилполисилоксаны являются продуктом основного органического синтеза, выпускаются в промышленных масштабах, обладают высокой гидрофобизирующей способностью, их применение позволяет регулировать агрегацию частиц в технологии карбоновых композитов. Целесообразность использования диметилполисилоксана обусловлена и другими причинами, такими как доступность реагента, экологическая безопасность, наличие в структуре ВМС атомов кремния. Атомы кремния, входящие в структуру молекул способствуют созданию адсорбционного слоя, который усиливает взаимодействие между частицами композитов - углерода и силикатной матрицы. Таким образом, изучение адсорбционной способности диметилполисилоксанов на углеродных сорбентах является актуальным.

\section{Теоретическая часть}

Адсорбция высокомолекулярных соединений на углеродных сорбентах исследована достаточно подробно и изложена в специальной литературе. Значительная часть исследований посвящена применению углеродных сорбентов различной природы и строения, которые используют в различных областях науки, техники, в частности, в медицине в технологии гемосорбции [1,2]. Разработаны специальные методы получения модифицированных сорбентов на основе углеродных частиц различной формы [3]. Большое внимание уделяется изучению строения адсорбционных слоев, в частности, особенностей конформации белковых молекул на поверхности углеродных сорбентов [4]. Исследования связаны с получением специальных материалов для адсорбции токсичных веществ, имеющих белковое происхождение. Как правило, сорбенты получают путем нанесения модификатора на углеродную поверхность. Далее проводят полимеризацию веществ, что обуславливает образование полимерной пленки на углеродной частице. Модификация поверхности указанным образом имеет и негативные последствия - образование полимера на поверхности углеродного сорбента приводит к уменьшению удельной величины поверхности материала и общего объема пор, снижая эффективность сорбента.

Модификацию поверхности можно проводить путем сорбции полимеров специального назначения из водных или неводных растворителей. Адсорбция ВМС имеет специфические особенности, такие как наличие конформационных изгибов на границе раздела фаз - способность сжиматься молекулы в клубок или распределяться по поверхности в линейном виде. Как правило, макромолекула ВМС обладает гибкостью, в адсорбционном слое ориентирована по отношению к поверхности адсорбента различными способами. В большинстве случаев при сжатии молекулы по-

Tихомирова и др. / Сорбционные и хроматографические процессы. 2020. Т. 20. № 4. С. 485-492 
лимера в клубок конформации не влияют на тип изотермы адсорбции, если не изменяется природа поверхности сорбента. Важная особенность при адсорбции ВМС заключается в том, что молекулы, которые адсорбируются не в виде клубка, касаются поверхности адсорбента много раз, что сказывается на энергии взаимодействия макромолекулы с поверхностью. Действительно, при энергии взаимодействия одного контакта на уровне физической адсорбции 4-12 кДж/моль, можно оценить суммарное взаимодействие макромолекулы с поверхностью при 10 контактах, которое будет равным энергии химической связи или специфического взаимодействия. Указанные особенности закрепления макромолекулы ВМС на поверхности сорбента обуславливают необратимость или неполную обратимость, которая наблюдается при адсорбции [5-8].

Следующая особенность при адсорбции полимера заключается в низкой скорости диффузии макромолекул, являющаяся следствием их большого размера, Указанный фактор обуславливает зависимость величин адсорбции от пористости адсорбента и наличия таких конформаций в адсорбционном слое, которые энергетически не выгодны. Если в макромолекуле полимера существуют функциональные группы, то на конформацию макромолекул влияет степень диссоциации. В качестве модели, характеризующей свойства макромолекулы на поверхности углеродного сорбента, рассмотрим адсорбцию поликарбоксилата. Методом Монте-Карло проведен расчет конформаций макромолекулы поликарбоксилата при адсорбции на различных адсорбентах [6]. Установлено, что на тип изотермы адсорбции влияет не столько природа сорбента, сколько кислотность раствора - распределение звеньев макромолекулы по поверхности сорбента зависит от константы диссоциации функциональных групп и кислотности растворов. В указанной работе [6] исследованы кривые титрования в гетерогенной системе раствор ВМС - адсорбент, представлена модель распределения цепей макромолекулы по поверхности адсорбента. В частности, было показано, что не только кислотность, но и ионная сила раствора влияет на полиэлектролит, изменяя степень ионизации макромолекулы и наличие конформационных изгибов.

Нами проведена реконструкция конформаций макромолекулы поликарбоксилата по отдельным фрагментам в соответствии с данными и методикой работы [6]. Получены качественные закономерности распределения макромолекулы поликарбоксилата по поверхности в зависимости от концентрации 1.1-валентного электролита (KOH, HCI) при различных значениях $\mathrm{pH}-\mathrm{pK}_{0}$, которые в виде схемы представлены на рис. 1.

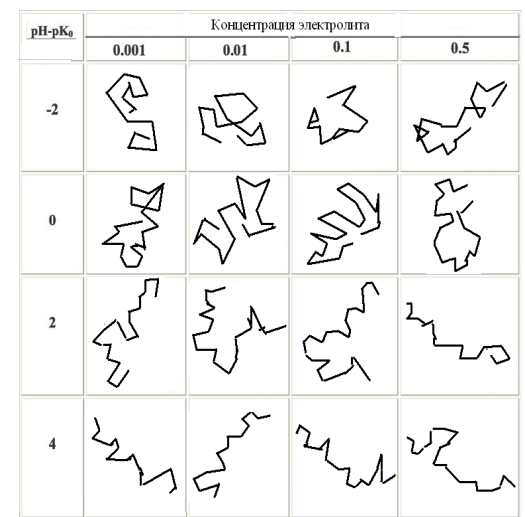

Рис. 1. Общий вид конформаций фрагментов макромолекулы поликарбоксилата на графите в электролитах $\mathrm{HCI}\left(\mathrm{pH}-\mathrm{pK}_{0}-2 ; 0\right), \mathrm{KOH}\left(\mathrm{pH}-\mathrm{pK}_{0} 2 ; 4\right)$

Fig. 1. Conformations of the fragments of the polycarboxylate macromolecule on graphite in the electrolytes $\mathrm{HCI}\left(\mathrm{pH}-\mathrm{pK}_{0}-2 ; 0\right), \mathrm{KOH}\left(\mathrm{pH}_{-} \mathrm{pK}_{0} 2 ; 4\right)$ 
При отрицательных или близких к нулю величинах $\mathrm{pH}-\mathrm{pK} \mathrm{K}_{0}$ степень ионизация слабая и близка к нулю. При достаточно больших значениях $\mathrm{pH}-\mathrm{pK}$ в во всех случаях диссоциация возрастает и вследствие сил электростатического отталкивания между отдельными участками макромолекула разворачивается, становится более линейной и в таком виде адсорбируется на поверхности. Величина адсорбции в первую очередь зависит не столько от природы поверхности, сколько от конформации макромолекулы в растворе и среднеквадратичного радиуса степени гидратации.

Цепи макромолекулы начинают расширяться при промежуточных значениях $\mathrm{pH}-\mathrm{pK} 0$ в зависимости от ионной силы раствора. Макромолекула становится более развернутой при концентрациях электролита $0.01 \mathrm{M}$ и значениях $\mathrm{pH}-\mathrm{pK}$, paвных 4-8, что согласуется с качественным конформационным анализом.

\section{Экспериментальная часть}

В качестве вещества, которое адсорбируется на поверхности углеродного вещества, применяли диметилполисилоксан марки ПМС-20. По внешнему виду это бесцветная жидкость, химически инертна, не токсична, обладает хорошими водоотталкивающими свойствами. ПМС-20 хорошо растворяется в органических растворителях, поэтому адсорбцию проводили из растворов гексана. В качестве адсорбентов использовали графит, уголь Донецкого бассейна антрацит, активированный уголь. Характеристики исследованных веществ представлены в табл. 1,2.

Таблица 1. Характеристики диметилполисилоксана ПМС-20

Table 1. Characteristics of dimethylpolysiloxane PMS-20

\begin{tabular}{|c|c|c|}
\hline Наименование параметра & Размерность & Величина \\
\hline $\begin{array}{c}\text { Средняя степень полимериза- } \\
\text { ции }\end{array}$ & $\mathrm{n}$ & $10-12$ \\
\hline Средняя молярная масса & Г/моль & 12000 \\
\hline Плотность при $20^{\circ} \mathrm{C}$, & $\Gamma / \mathrm{cm}^{3}$ & 0.96 \\
\hline Температура кипения & ${ }^{\circ} \mathrm{C}$ & 250 \\
\hline Температура застывания & ${ }^{\circ} \mathrm{C}$ & -66 \\
\hline
\end{tabular}

Таблица 2. Физико-химические свойства исследованных углеродных веществ Table 2. Physico-chemical properties of the studied carbon substances

\begin{tabular}{|c|c|c|c|c|c|c|c|}
\hline \multirow{2}{*}{ Уголь } & \multirow{2}{*}{$\begin{array}{c}\text { Марка, символ } \\
\text { угля } \\
\end{array}$} & \multicolumn{5}{|c|}{ Технический и элементный анализ } & \multirow{2}{*}{$\begin{array}{l}\mathrm{S}_{\text {уд., }} \\
\mathrm{M}^{2} / \Gamma\end{array}$} \\
\hline & & $\mathrm{A}^{\mathrm{c}, \%}$ & $\mathrm{C}^{\Gamma}, \%$ & $\mathrm{~S}^{\mathrm{c}}, \%$ & $\mathrm{~N}+\mathrm{O}, \%$ & $\mathrm{H}, \%$ & \\
\hline Антрацит & А, Стеклянный & 3.8 & 94 & 0.35 & 1.1 & 1.3 & 13 \\
\hline Графит & $\begin{array}{c}\text { Спектральный, } \\
\text { С-3 }\end{array}$ & $<0.1$ & $>99$ & - & - & - & 0.54 \\
\hline $\begin{array}{c}\text { Уголь } \\
\text { активный }\end{array}$ & Б & 2 & $>97$ & - & - & - & 800 \\
\hline
\end{tabular}

Построение изотерм адсорбции осуществляли следующим образом. Диметилполисилоксан взвешивали, растворяли в гексане, рассчитывали концентрацию вещества. Навеску угля помещали в колбу объемом $50 \mathrm{~cm}^{3}$ с притертой стеклянной пробкой, добавляли $20 \mathrm{~cm}^{3}$ раствора диметилполисилоксана. Адсорбцию проводили до установления равновесия (5 часов). Суспензию фильтровали, отбирали $10 \mathrm{~cm}^{3}$ раствора, помещали в пластиковый стакан, взвешенный с точностью до 0.00001 г, гексан испаряли при температуре $40-50{ }^{\circ} \mathrm{C}$. Расчет величины адсорбции (мг/г) проводили по формуле 1: 


$$
\Gamma=\frac{m_{2}-m_{1}}{M},
$$

где $m_{1}, m_{2}, M$ - соответственно масса диметилполисилоксана в растворе до и после адсорбции мг, масса навески адсорбента, г.

Расчет площади посадки молекулы диметилполисилоксана проводили по отдельным фрагментам химических связей с помощью программы «ChemOffice» v.8, оптимизируя расположение молекулы по принципу наименьшей энергии [9].

\section{Обсуждение результатов}

Изотермы адсорбции диметилполисилоксана на графите C-3, антраците, активированном угле представлены на рис. 2-4.

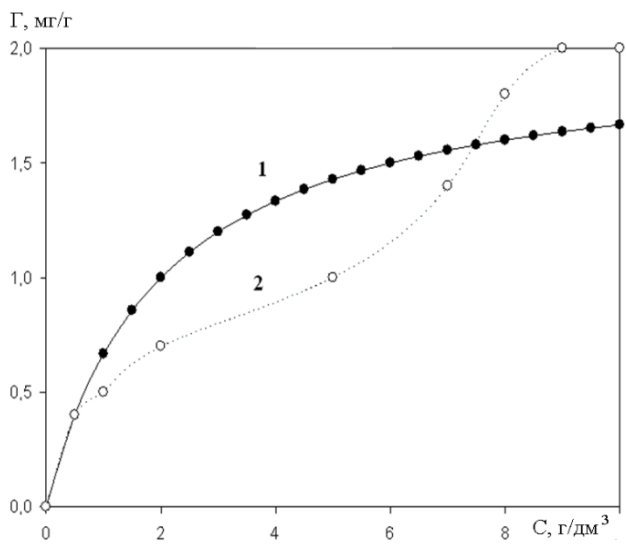

Рис. 2. Адсорбция диметилполисилоксана на графите (298 К).

1,2 - расчетные величины по изотерме Ленгмюра, экспериментальные значения

Fig. 2. Adsorption of dimethylpolysiloxane on graphite (298 K). 1,2 - values calculated using the Langmuir isotherm, experimental values

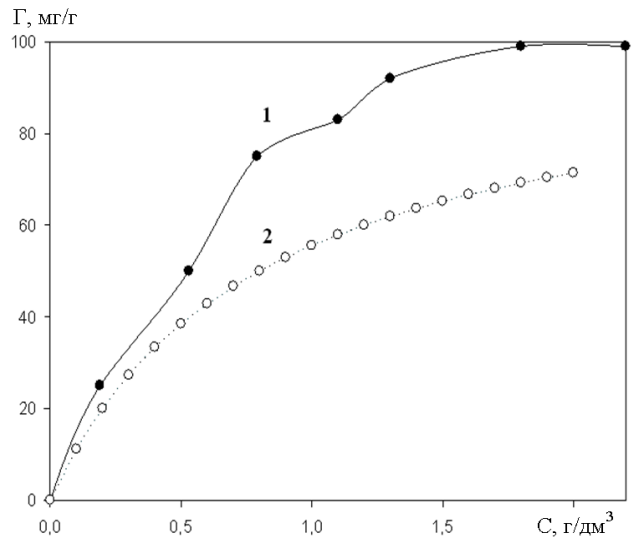

Рис. 3. Изотерма адсорбции диметилполисилоксана из гексана на антраците (298 К).

1,2 - экспериментальные величины, расчетные значения по изотерме Ленгмюра

Fig. 3. Adsorption isotherm of dimethylpolysiloxane from hexane on anthracite (298 K). 1,2 - experimental values calculated using the Langmuir isotherm

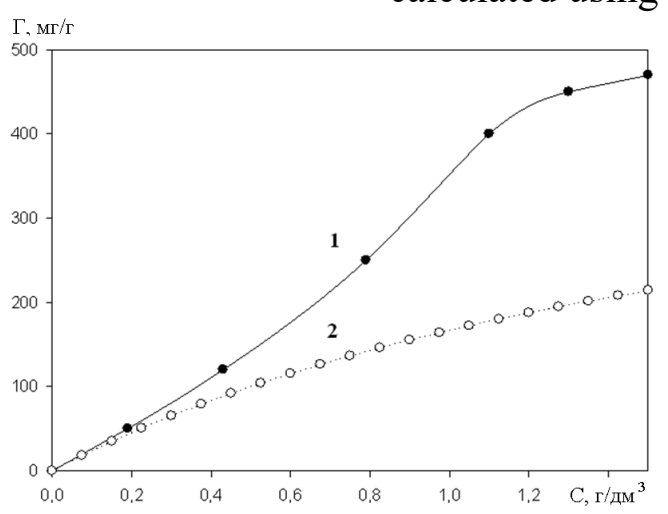

Рис. 4. Изотерма адсорбции диметилполисилоксана из гексана на активном угле Б (298 К). 1,2 - экспериментальные значения, расчетные значения по изотерме Ленгмюра

Fig. 4. Adsorption isotherm of dimethylpolysiloxane from hexane on activated carbon B (298 K). 1,2 - experimental values calculated using the Langmuir isotherm 
Оптимизируя расположение макромолекулы диметилполисилоксана на поверхности графита по принципу наименьшей энергии, можно установить, что из гексана молекула адсорбируется в виде глобулы, площадь посадки которой равен $2 \cdot 10^{-18} \mathrm{M}^{2}$ (эквивалентный радиус макромолекулы ПМС-20 равен $4.5 \cdot 10^{-10}$ м). Удельная поверхность графита С-3 равна $0.54 \mathrm{~m}^{2} / \Gamma$, поэтому расчетная адсорбционная способность графита должна находиться в пределах от 5 до 6 мг/г. По экспериментальным данным адсорбционная способность графита равна 2 мг/г, рис. 2. Следовательно, часть адсорбционных центров не заполнена (например, полярные участки адсорбента). Вторая причина, по которой адсорбционная способность графита может быть меньше расчетной, может быть связана конформационными изменениями - макромолекула находится в «развернутом» состоянии и занимает площадь посадки больше, чем $2 \cdot 10^{-18} \mathrm{~m}^{2}$, что маловероятно. Проведя расчет константы адсорбционного равновесия при экстраполяции равновесной концентрации диметилполисилоксана к нулю, принимая величину максимальной адсорбции 2 мг/г, построим изотерму адсорбции Ленгмюра расчетным методом, рис. 2. Заполнение адсорбционного слоя при величинах равновесной концентрации до 7.5 г/дм³ происходит медленнее, чем по изотерме Ленгмюра. В экспериментальной изотерме при концентрациях более 7.5 г/дм ${ }^{3}$ адсорбционная способность возрастает и выходит на плато. В результате изотерма адсорбции имеет $s$-образный вид. Можно предположить, что на поверхности графита идет заполнение адсорбционных центров двух различных видов - гидрофобных и гидрофильных, но по типу изотерма адсорбции не является изотермой Ленгмюра. Вероятно, на адсорбционную способность глобул диметилполисилоксана влияет аттракционное взаимодействие (отталкивание макромолекул) и заполнение адсорбционного слоя происходит более медленно на начальных стадиях адсорбции.

В отличие от графита на антраците и активном угле Б с удельной поверхностью $13 ; 800 \mathrm{~m}^{2} / \Gamma$ соответственно изотермы адсорбции имеют плато при концентрациях 1.4 ..1.5 г/дм³ Несмотря на то, что по виду изотермы адсорбции имеют сходство с изотермой адсорбции Ленгмюра, в реальности заполнение адсорбционного слоя происходит более интенсивно. Вероятно, на заполнение адсорбционного слоя оказывает фактор пористости углей.

Действительно, антрациты, активные угли обладают большим количеством пор, поэтому высокий адсорбционный потенциал способствует быстрому заполнению поверхности. Расчетные значения максимальной величины адсорбции для антрацитов и активных углей составляют 130, 768 мг/г.

Указанные закономерности можно объяснить тем, что некоторая часть пористого пространства не доступна для адсорбции макромолекул ПМС-20 вследствие стерических затруднений.

Таким образом, изучение адсорбционной способности графитов, антрацитов, активных углей позволяет установить концентрации гидрофобизатора для различных типов сорбентов, что важно в технологии модификации поверхности углеродных сорбентов высокомолекулярными соединениями.

\section{Заключение}

Выявлены закономерности адсорбционной способности диметилполисилоксана (ПМС-20) из неводного растворителя (гексан) на графите C-3, антрацитах, активированном угле «Б». Проведено сопоставление расчетных изотерм Ленгмюра с изотермами адсорбции, полученными на практике. Показано, что экспериментальные изотермы не совпадают с изотермами адсорбции Ленгмюра.

Tихомирова и др. / Сорбционные и хроматографические процессы. 2020. Т. 20. № 4. С. 485-492 
Вероятно, что на графите C-3 заполнение адсорбционного слоя осуществляется по двум видам адсорбционных центров и происходит медленнее, чем при адсорбции Ленгмюра,

На пористых углеродных адсорбентах (антрацит, активированный уголь) заполнение адсорбционного слоя более интенсивно, чем при адсорбции Ленгмюра. Вероятно, на заполнение адсорбционного слоя оказывает фактор пористости углей. Расчетные значения максимальной величины адсорбции для антрацитов и активных углей составляют 130,768 мг/дм².

На антраците и активном угле Б с удельной поверхностью $13,800 \mathrm{~m}^{2} / \Gamma$ соответственно изотермы адсорбции имеют плато при концентрациях $1.4 \ldots 1.5$ г/дм ${ }^{3}$, что соответствует предельной величине адсорбции 100, 480 мг/г.

\title{
Список литературы
}

1. Николаев В.Г., Стрелко В.В. Гемосорбция на активированных углях. Киев. Наукова думка. 1979.288 с.

2. Рачковская Л.Н. Углеродминеральные сорбенты для медицины. Новосибирск. СО PACXH. 1996. $231 \mathrm{c}$.

3. Hemei Chen. // Proteomics. 2009. Vol. 9. pp. 380-387.

4. Седанова А.В. Автореф. дисс. на соиск. уч. степ. канд. хим. наук. Омск. ОГТУ. 2012. $23 \mathrm{c}$.

5. Кулешова И.Д. Макромолекулы на границе раздела фаз. Киев. Наукова думка.
1971. C. $100-104$

6. Laguecir A., Stoll S. // Polymer. 2005. No 46. pp. 1359-1372.

7. Кирсанова К.А. // Международный журнал экспериментального образования. 2010. № 1. С. $45-45$

8. Цветков В.Н., Эскин В.Е., Френкель С.Я. // В кн.: Структура макромолекул в растворах. М. Наука. 1964. С. 65-68.

9. Тихомирова К.В. Автореф. дисс. на соиск. уч. степ. канд. тех. наук. Белгород. БГТУ. 2018. 23 с.

\section{Adsorption of dimethylpolysiloxane on graphite, anthracite, and activated carbon from hexane solutions}

\author{
(C) 2020 Tikhomirova K.V., Lopanov A.N. \\ Belgorod State Technological University named after V. G. Shukhov, Belgorod
}

\begin{abstract}
The article presents an analysis of the features of adsorption of high molecular substances on porous carbon adsorbents. These features include the low diffusion rate of macromolecules, the dependence of the adsorption on the porosity of the adsorbent, and the presence of the conformations in the adsorption layer that are not energetically beneficial. The conformations of the polycarboxylate macromolecule were reconstructed using individual fragments. We also obtained qualitative regularities of the distribution of the polycarboxylate macromolecule over the surface depending on the concentration of the 1.1-valence electrolyte at various $\mathrm{pH}-\mathrm{pK}_{0}$. When the $\mathrm{pH}-\mathrm{pK}_{0}$ are negative or close to zero, the degree of ionization is low and close to zero. When $\mathrm{pH}-\mathrm{pK}_{0}$ are sufficiently high, the dissociation increases in all cases and, due to electrostatic repulsion forces between certain sections, the macromolecule unfolds, becomes more linear, and is adsorbed on the surface in this form. The amount of adsorption does not depend much on the nature of the surface, but rather depends on the conformation of the macromolecule in the solution and the root mean square radius of the degree of hydration. In our research, we also studied the adsorption of dimethylpolysiloxane (PMS-20) from solutions of the substance in hexane on graphite C-3, activated carbon B, and A grade fossil coal from the Donetsk basin (glass layer). The study determined the adsorption mechanisms and demonstrated that the adsorption isotherms of this type do not correspond to the Langmuir adsorption isotherms. The adsorption layer is filled more slowly on graphite, and more intensively on anthracite and activated carbon than during Langmuir adsorption. It was suggested that during the adsorption of dimethylpolysiloxane on graphite, the globules of macromolecules repel each other, while the high adsorption potential on anthracite and activated carbon contributes to more intense filling of the adsorption layer. The study determined the maximum adsorp-
\end{abstract}


tion capacity of the studied adsorbents with respect to dimethylpolysiloxane, equal to graphite, anthracite, and activated carbon to be 2,100 , and $480 \mathrm{mg} / \mathrm{g}$ respectively. The calculated values of the maximum adsorption capacity of adsorbents are 6,130 , and $768 \mathrm{mg} / \mathrm{g}$ respectively. Some parts of the porous space of anthracite and activated carbon are not available for adsorption of dimethylpolysiloxane macromolecules due to steric difficulties.

Keywords: adsorption isotherms, dimethylpolysiloxane, graphite, anthracite, activated carbon.

\section{References}

1. Nikolaev V.G., Strelko V.V., Gemosorbtsiya na aktivirovannykh uglyakh, Kiev, Naukova dumka, 1979, 288 p.

2. Rachkovskaya L.N., Uglerodmineral'nye sorbenty dlya meditsiny, Novosibirsk, SO RASKhN, 1996, 231 p.

3. Hemei Chen, Proteomics, 2009, Vol. 9, pp. 380-387.

https://doi.org/10.1002/pmic.200800335

4. Sedanova A.V., diss. cand. chem. nauk. Omsk, 2012, 23p .

Тихомирова Ксения Владимировна - к.т.н., доцент кафедры Безопасности жизнедеятельности, Белгородский Государственный Технологический Университет им. В. Г. Шухова, Белгород

Лопанов Александр Николаевич - д.т.н., профессор кафедры Безопасности жизнедеятельности, Белгородский Государственный Технологический Университет им. В. Г. Шухова, Белгород
5. Kuleshova I.D., Makromolekuly na granitse razdela faz, Kiev, Naukova dumka, 1971. pp. 100-104.

6. Laguecir A., Stoll S., Polymer, 2005, No 46, pp. 1359-1372. DOI: $10.1016 /$ j.polymer. 2004.11.072

7. Kirsanova K.A., International journal of experimental education, 2010, No 1, pp. 45-45

8. Tsvetkov V. N., Eskin V.E., Frenkel' S.Ya., V kn.: Struktura makromolekul v rastvorakh, M., Nauka, 1964, pp. 65-68.

9. Tikhomirova K.V., diss. cand. tekh. Nauk, Belgorod, 2018, 23 p.

Tikhomirova Ksenya V. - Ph.D. (technic), associate professor department of life safety Belgorod State Technological University named by Vladimir Grigorevich Shuhov (BSTU ), Belgorod, mssksenya@mail.ru

Lopanov Alexander N. - prof., grand Ph.D (chemistry), department of life safety Belgorod State Technological University named by Vladimir Grigorevich Shuhov (BSTU ), Belgorod, alopanov@yandex.ru 